\title{
Development of a vacuum-packing system for food waste from urban catering facilities
}

\author{
Federico Ciuffa BSc, MSC \\ Researcher, Department of Civil and Environmental \\ Engineering, Imperial College London, \\ London, UK \\ Jeff Cooper BSC, MSC, FRSG, FCIWM \\ Honorary Editor, ICE Waste and Resource Management Journal, \\ member of the Hospitality and Food Service Working \\ Group for Courtauld 2025 (C2025), past president of ISWA \\ independent consultant, London, UK
}

\author{
Sue Grimes BSc, PhD, MBA, Dip, MRS, CChem, CSci, FRSC, \\ CEnv, FCIWM \\ Royal Academy of Engineering Professor of Waste \& Resource \\ Management, Department of Civil and Environmental Engineering, \\ Imperial College London, London, UK (corresponding author: s.grimes@ \\ imperial.ac.uk)
}

Stephen R. Smith BSC, PhD, MCIWM, MCIWEM, CWEM, CEnv Professor of Bioresource Systems, Department of Civil and Environmental Engineering, Imperial College London, London, UK

A novel vacuum-packing system is developed for food waste storage and collection under the conditions found in high-density urban and metropolitan catering establishments that has the following beneficial outcomes: (a) a reduction of $38 \%$ in the volume of food waste to be stored for collection; (b) a reduction in the physical space required on-site for storage of multiple vacuum packs of waste; (c) containment of the food waste stored in sanitised conditions, thus maintaining the integrity of the waste and extending the useful life of the waste in terms of its ideal composition for optimum beneficial recovery by anaerobic digestion or in-vessel composting, and reducing problems due to odour and vermin; and $(d)$ reduction in the number of vehicle movements required to transfer the wastes to treatment facilities and their environmental impacts, while also achieving savings of $f 13-16$ per bin lift in London, along with a considerable reduction in overall cost.

\section{Introduction}

The issue of food waste has become increasingly recognised as a global sustainability problem (Parfitt et al., 2010) with major adverse environmental, social and economic impacts; it is now acknowledged as sufficiently significant to be recognised by the United Nations as one of their sustainable development goals, with a target of $50 \%$ reduction in food waste globally by 2030 (UN, 2016). There are different sources of food waste throughout the supply chain from farm to fork (Okazaki et al., 2008) and their significance varies from developing countries to developed economies (Parry et al., 2015). Food waste generated in the hospitality and food sector presents a particular challenge and a number of studies have been carried out on the characterisation and reduction of this waste, including the following. (a) Development of a framework for the study of waste generation and prevention using a hotel restaurant complex in Malaysia as a case study (Papargyropoulou et al., 2016). (b) The use of life-cycle assessment to investigate the main environmental impacts from operating a restaurant or food service (Baldwin et al., 2001). (c) The use of measurement of non-renewable energy consumed as a food chain evaluator tool for analysing environmental impacts from institutional catering establishments in Italy (Caputo et al., 2017). (d) Development and adoption of a model of environmental practices and impacts (primarily in the financial and operational spheres) on independent hotels in Spain and Chile (Alonso-Almeida et al., 2017). (e) A materials flow analysis of the food waste generated in hotels and restaurants in Abu
Dhabi along with a carbon footprint analysis of disposed food waste from chosen events that showed the factors contributing most significantly to food waste generation included serving style, timing and type of food served; accuracy of the prediction of the number of customers expected was also a factor because it allowed for the use of a number of minimisation strategies for food waste in this sector (Pirani and Arafat, 2016). ( $f$ ) A characterisation and evaluation case study on the generation and collection of restaurant waste in Italy (Tatano et al., 2017).

In the United Kingdom, the hospitality and food service (HaFS) sector generates almost 1 million tonnes per annum (tpa) of food waste, $21 \%$ of which arises from spoilage, $45 \%$ from food preparation and 34\% from plate waste (Parry et al., 2015). In 2012, The Hospitality and Food Service Agreement (HaFSA) was set up under the auspices of the UK government's Waste and Resource Action Programme as a 3-year programme to encourage the sector to reduce overall waste and particularly food waste. The organisations, companies and premises participating in this programme were encouraged to follow a resource management hierarchy to achieve an overall reduction in waste to ensure both greater economic and environmental benefits for their businesses. The final report of HaFSA, published in 2017 (WRAP, 2017) highlighted the successes of the programme in reducing the HaFS food waste as: $(i)$ an overall reduction in catering food waste of $11 \%$; (ii) $24000 \mathrm{t}$ of food waste (worth $£ 67$ million) avoided over the lifetime of the project; (iii) a reduction in carbon dioxide equivalent resulting from reductions 
in food and packaging waste generation; and (iv) an increase in food and packaging waste recycling by way of composting or anaerobic digestion (AD) from 42 to $56 \%$ over the lifetime of the project. Since the conclusion of the HaFSA programme, the HaFS sector has continued its efforts on waste prevention, reuse and recycling under the Courtauld Commitment 2025 (WRAP, 2016a) and the Food Waste Recycling Action Plan (WRAP, 2016b).

In the results of a study of the true cost of food waste in the HaFS sector in the United Kingdom (Lee et al., 2013; WRAP, 2013), it was reported that the cost to the restaurant sub-sector of dealing with their 200000 tpa arisings was almost $£ 3500 / t$ in 2011. This cost arose from a number of factors including: food purchases, labour, utility costs and waste management. About $7 \%$ of this food waste was disposed to sewers through sink disposal units while $80 \%$ of it ended up in residual waste containers and was not treated by AD or in-vessel composting (IVC).

The main difficulty faced by restaurant premises, particularly in areas of high population density, is that they frequently lack space and facilities to segregate food waste into viable fractions, particularly because catering establishments prefer to focus on separating out dry recyclable waste from packaging items, thus exacerbating the problem of lack of storage space. As a consequence, in early 2017 , fewer than $10 \%$ of UK restaurants separated out food waste for treatment to improve environmental impacts and recover value. In economic and environmental terms, the technology regarded as the best option for treating segregated food waste in the United Kingdom, and increasingly internationally, is $\mathrm{AD}$, where the bio-methane produced is used as a fuel either directly or in situations such as upgrading for gas grid injection, use as a vehicle fuel or for electricity generation. The non-fuel solid digestate residue from $\mathrm{AD}$ can also be used, after further treatment, as a soilenhancing agent. The second most popular choice of technology for segregated food waste treatment is IVC, where closed-loop options can result in the production of highquality PAS 100 composts (Gomez et al., 2008; BSI, 2011).

Most studies on food waste in the hospitality sector deal with characterisation and reduction of the waste, but there have been no significant reports on the development of improved methodologies to deal effectively with the safe transfer of catering food waste to treatment facilities. Although vacuumpumping methods are already commonly used by restauranteurs and facility-management companies, for health and safety reasons where there is the risk of spillage of liquids, they have not been used in handling food waste for waste collection or improving value recovery from food waste. The authors now report, using a case study involving restaurants in a highpopulation-density urban area in central London, on the use of a novel system of vacuum-packing designed to: $(a)$ contain the food waste and reduce the volume that has to be stored, particularly in situations where space is at a premium; $(b)$ extend the useful life of the waste in terms of its ideal composition for recovery of value by $\mathrm{AD}$ and IVC; and $(c)$ minimise environmental problems associated with vermin and odours.

\section{Methodology}

The research on developing a workable solution for collecting food waste from space-constrained restaurant premises in highdensity urban areas to maximise the amounts of food waste treated beneficially by AD or IVC was carried out in three parts: (i) selection of restaurants for use in the case study and characterisation of their food waste arisings; (ii) the development of a vacuum-packing system to maximise the capture of food waste for value recovery; and (iii) information gathering through a survey involving staff of the selected restaurants designed to determine catering staff attitudes to proposed changes in food waste collection.

\subsection{Selection of case study restaurants and characterisation of their food waste arisings}

\subsubsection{Choice of restaurant as case study}

The three restaurants chosen for the case studies were situated in the Kensington area of central London. Each restaurant already had some segregation of their food waste and their management systems were independent of any control from chain restaurant head offices. At all three restaurants it was possible to assess the overall provisions made for separation, storage and collection of food waste to provide the information necessary to permit both characterisation of the food waste and of their methods of collection of the waste for treatment. The three restaurants participating in the study differed in the cuisine they offered: restaurant A (with $\sim 400$ covers per week) followed a healthy fine dining style of cuisine with relatively small plate portions and a high fresh vegetable content; restaurant B (with $\sim 600$ covers per week), located in a more residential area, made use of pre-cleaned and prepared ingredients, for example the meat and fish used was generally delivered pre-boned and skinned; and restaurant $\mathrm{C}$ (with $\sim 800$ covers per week) was an all-day bar providing a lunch and dinner service, again using a significant quantity of cleaned and prepared ingredients. Other differences between the restaurants included: (i) their in-house methods for preparation of ingredients; (ii) their approach to food waste prevention and recovery; (iii) their opening hours; and (iv) the status of their owners and the influence of their chefs, thus providing three different situations for studies on the development of food waste containment methodology.

\subsubsection{Characterisation of the food waste arisings}

The fractions of food waste that were used to measure the quantities of waste in different categories were designed to permit a detailed assessment of the environmental impacts of 
the different types of food waste and provide a means of assessing the advantages that might accrue from the development of methods of containing the food waste prior to transfer to treatment facilities. The fractions used were: vegetables, fruit, potatoes, meat, fish, bread, bakery, pasta and rice, dairy, and plate waste. As part of the research, the food waste was separated into these fractions from the restaurants and the weights within each fraction were measured for each restaurant over a period of seven consecutive full working days of $14.5 \mathrm{~h}$ (from 10.00 a.m. to 00.30 a.m.) during June and July 2016. Food waste from the restaurants was collected for characterisation in 5 litre capacity vessels and weighed to an accuracy of $0 \cdot 1 \mathrm{~g}$ for each separated waste fraction, and for mixed preparation waste and plate waste that was not further fractionated into its components.

\subsection{Development of a vacuum-packing system methodology to maximise capture of food waste for value recovery}

There have been no previous reports on the extensive use of vacuum-packing systems for the containment of food wastes produced in catering establishments in high-density urban areas where storage space is at a premium. A vacuum-packing system is developed in this work as both an aid to caterers and waste contractors for handling and storing of the waste, and as a means of extending the useful life of the waste in terms of its ideal composition for maximum beneficial value recovery.

The vacuum system used to collect food wastes in plastic bags was a wet and dry system (Numatic WVD-2000-2) with a capacity of 70 litres that was capable of pumping the collected wastes and fluids. The efficiency of the containment system and the preservation of waste for recycling was determined by measurements on the changes in volume of the waste on packing and changes in the $\mathrm{pH}$, moisture content and volatile organic compound (VOC) composition of the dried waste with time. All experiments were carried out in triplicate.

The procedure used to determine the volume reduction resulting from vacuum-packing was to measure the difference between the displacement of water from a 16 litre reservoir of weighed amounts of food waste in sealed plastic bags and the same amounts of waste in the bags after vacuum evacuation. The possible deterioration of the food waste in sealed bags was determined by measuring the $\mathrm{pH}$, moisture content and VOC content of the dried vacuum-packed waste over a period of $5 \mathrm{~d}$. The $\mathrm{pH}$ was measured on 1:3 mixtures of vacuum-packed food waste and deionised water using a Fisherbrand Hydrus 500 , fitted with a gel-filled plastic-bodied combined $\mathrm{pH}$ electrode; moisture content was determined by measuring the weight loss from samples of the vacuum-packed food waste after drying samples in an oven for a period of $24 \mathrm{~h}$ at $105^{\circ} \mathrm{C}$; and VOC measurements were made on the dried samples of food waste ignited at $550^{\circ} \mathrm{C}$ according to the American Public Health Association standard 2540E (APHA, 2016).

\subsection{Survey of food waste practices}

A survey was carried out through face-to-face interviews with staff of the selected restaurants to assess the potential for the introduction of a vacuum-packing system for food waste collection and storage in catering establishments in highdensity urban areas. The survey was conducted at the three case study restaurants to obtain information on the knowledge that their staff have on the principles of food waste management and on the potential benefits or otherwise of the use of the vacuum-packing system. The face-to-face interviews were based on a questionnaire (Table 1) methodology

Table 1. Survey questionnaire used to encourage responses in face-to-face interviews

\section{General questions}

What is the biggest challenge you face in disposing of food waste appropriately in terms of separation and storage?

What could be done to increase staff involvement in separating food waste?

- How important is the involvement of senior staff (managers, chefs etc.) in terms of their awareness of, and influence on, correct food waste collection?

- How difficult do you think it would be to change methods of food waste collection in your restaurant?

\section{Questions on current waste disposal}

- How often is food waste collected from the restaurant?

Where is the food waste collected from?

- Does the waste collection procedure used have any impact on clients?

What is the cost of the food waste collection from the restaurant?

- Is your current food waste collection system effective or have you encountered problems?

- Are the waste collection bags supplied by you or your waste collection contractor?

\section{Questions on the vacuum-packing system used in the} research

Would you consider using a vacuum-packing system for food waste management?

- How feasible would it be for the establishment to use a wet and dry vacuum system to contain waste food in plastic bags for storage?

- If you introduced a vacuum-packing system would you prefer to purchase or hire the required equipment for use in your restaurant?

- What are your views on the potential benefits that could result from use of a vacuum-packing system for food waste management?

- Do you perceive any disadvantages in the use of a vacuum-packing system in your restaurant? 
developed and used by the research group in earlier studies (Hume et al., 2002), and was designed to obtain information on environmental impacts by use of questions that did not elicit specific responses from the interviewees.

\section{Results}

\subsection{Case study restaurants and characterisation of their food waste arisings}

The results on the characterisation of the food waste in the three restaurants A, B and C are in Tables $2-4$, respectively, with the plate waste representing the largest single quantity of the waste collected at $37 \cdot 5,48 \cdot 1$ and $52 \cdot 1 \%$, respectively. As restaurants $\mathrm{B}$ and $\mathrm{C}$ make use of pre-cleaned and pre-selected ingredients, all of the separated food waste was efficiently fractionated into the various categories with zero mixed preparation waste recorded. For restaurant A, however, on two of the seven days, some mixing of the preparation waste fractions occurred accounting for $2.7 \%$ of the total food waste collected during the week.

\subsection{Development of a vacuum-packing system methodology to maximise capture of food waste for value recovery}

The vacuum-packing system methodology developed for the storage of food waste in catering establishments for collection is shown in the schematic diagram in Figure 1. The use of the system results in: (i) a reduction of $38 \%$ in the volume of food waste to be stored for collection in evacuated plastic bags that, when filled, can effectively be flat-packed, (ii) storage of food waste under sanitised conditions prior to collection, with a consequent decrease in biological deterioration, supported by the negligible changes (Table 5) in $\mathrm{pH}$, moisture content and VOC of the dried food waste content of the vacuum-packed waste over a period of $5 \mathrm{~d}$.

\subsection{The food waste survey}

The food waste survey carried out in the three case study restaurants under the heading 'General questions' confirmed that the major problems associated with waste generation in

Table 2. Characterisation of food waste from restaurant $A$

\begin{tabular}{|c|c|c|c|c|c|c|c|}
\hline & \multicolumn{7}{|c|}{ Food waste collected daily: $\mathbf{g}$} \\
\hline & Monday & Tuesday & Wednesday & Thursday & Friday & Saturday & Sunday \\
\hline Bakery & 231 & 448 & 18 & 800 & 390 & 200 & 0 \\
\hline Dairy & 430 & 256 & 60 & 768 & 502 & 1242 & 119 \\
\hline Fish & 1834 & 1075 & 4499 & 3581 & 1347 & 4127 & 1137 \\
\hline Meat & 706 & 3163 & 6662 & 5110 & 266 & 2880 & 142 \\
\hline Pasta/rice & 10 & 0 & 31 & 0 & 0 & 61 & 21 \\
\hline Potatoes & 156 & 0 & 0 & 0 & 99 & 47 & 315 \\
\hline Vegetables & 10419 & 10134 & 6040 & 5042 & 12714 & 7531 & 3710 \\
\hline Fruit & 789 & 1966 & 3271 & 3038 & 682 & 2367 & 1079 \\
\hline Mixed preparation & 2245 & 0 & 0 & 0 & 2819 & 0 & 0 \\
\hline Total preparation waste & 16820 & 17042 & 20581 & 18339 & 18819 & 18455 & 6523 \\
\hline Plate waste & 13863 & 7897 & 14272 & 7810 & 6249 & 10675 & 9071 \\
\hline Total food waste & 30683 & 24939 & 34853 & 26149 & 25068 & 29130 & 15594 \\
\hline
\end{tabular}

Table 3. Characterisation of food waste from restaurant B

\begin{tabular}{lrrrrrrr} 
& \multicolumn{7}{c}{ Food waste collected daily: $\mathbf{g}$} \\
\cline { 2 - 7 } & Monday & Tuesday & Wednesday & Thursday & Friday & Saturday & Sunday \\
\hline Bakery & 0 & 92 & 0 & 0 & 14 & 206 & 0 \\
Dairy & 95 & 116 & 0 & 444 & 3985 & 162 & 243 \\
Fish & 235 & 1728 & 787 & 11735 & 726 & 192 & 302 \\
Meat & 3984 & 500 & 25 & 560 & 36 & 3082 & 799 \\
Pasta/rice & 0 & 18 & 43 & 17 & 0 & 8 & 23 \\
Potatoes & 49 & 1659 & 1306 & 0 & 2278 & 2174 & 0 \\
Vegetables & 1650 & 1734 & 1900 & 2052 & 0 & 229 & 1788 \\
Fruit & 480 & 955 & 1347 & 233 & 458 & 450 & 472 \\
Total preparation waste & 6493 & 6802 & 5408 & 15041 & 7497 & 6503 & 3627 \\
Plate waste & 9252 & 5845 & 5064 & 6904 & 8627 & 4567 & 7437 \\
Total food waste & 15745 & 12647 & 10472 & 21945 & 16124 & 11070 & 11064
\end{tabular}


Table 4. Characterisation of food waste from restaurant $C$

\begin{tabular}{|c|c|c|c|c|c|c|c|}
\hline & \multicolumn{7}{|c|}{ Food waste collected daily: g } \\
\hline & Monday & Tuesday & Wednesday & Thursday & Friday & Saturday & Sunday \\
\hline Bakery & 0 & 62 & 0 & 0 & 20 & 0 & 0 \\
\hline Dairy & 433 & 782 & 145 & 231 & 387 & 764 & 69 \\
\hline Fish & 0 & 217 & 591 & 0 & 0 & 174 & 0 \\
\hline Meat & 0 & 54 & 18 & 0 & 23 & 14 & 0 \\
\hline Pasta/rice & 0 & 0 & 0 & 0 & 0 & 52 & 0 \\
\hline Potatoes & 0 & 0 & 0 & 0 & 0 & 308 & 0 \\
\hline Vegetables & 3357 & 4029 & 3871 & 3465 & 2671 & 2270 & 3682 \\
\hline Fruit & 6014 & 6328 & 6092 & 5790 & 4394 & 4382 & 5889 \\
\hline Total preparation waste & 9804 & 11472 & 10717 & 9486 & 7495 & 7964 & 9640 \\
\hline Plate waste & 9533 & 14477 & 12632 & 10080 & 7032 & 9710 & 9400 \\
\hline Total food waste & 19337 & 25949 & 23349 & 19566 & 14527 & 17674 & 19040 \\
\hline
\end{tabular}

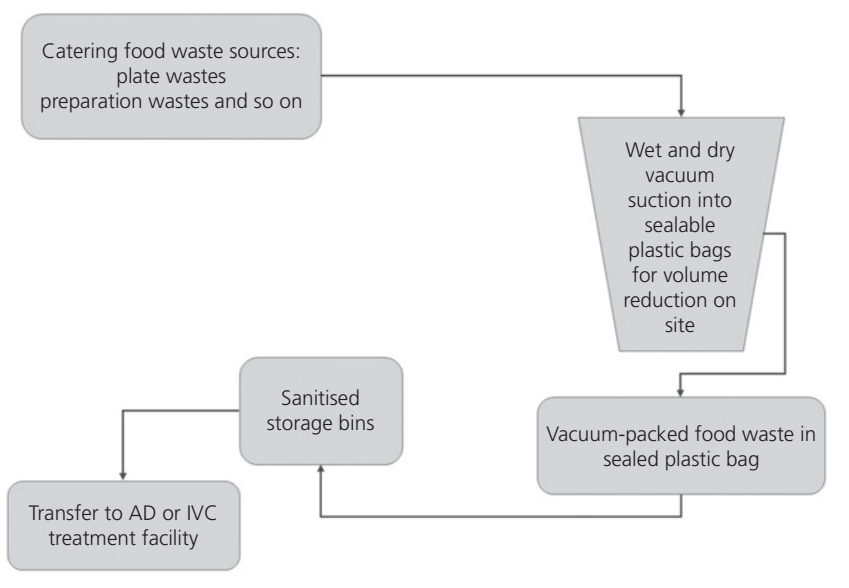

Figure 1. Schematic diagram of vacuum-packing system methodology

Table 5. Changes in $\mathrm{pH}$, moisture content and VOC content in vacuum-packed food waste over $5 \mathrm{~d}$

\begin{tabular}{lcr|} 
Measurement & $\begin{array}{c}\text { On vacuum } \\
\text { packing }\end{array}$ & \multicolumn{1}{c|}{ After $\mathbf{5}$ d } \\
\hline pH & $4 \cdot 27 \pm 0.09$ & $4 \cdot 30 \pm 0 \cdot 19$ \\
Moisture: \% & $60 \cdot 70 \pm 0.02$ & $51 \cdot 65 \pm 0.09$ \\
$\begin{array}{l}\text { VOC: \% on dried food } \\
\quad \text { waste }\end{array}$ & $96 \cdot 67 \pm 0.01$ & $97 \cdot 33 \pm 0.01$ \\
& & \\
\end{tabular}

catering establishments in high-population-density urban areas arise from severe space restrictions for waste storage and the fact that these establishments experience a rapid turnover of staff that leads to difficulties in maintaining consistent food waste separation practice for collection on a long-term basis. There was also general agreement that the involvement of senior restaurant staff in terms of their awareness of, and influence on, separation and collection of food waste was important in increasing staff involvement in the separation and collection process. Among the senior staff there appeared to be no barriers to changing the methods of food waste collection in the restaurants, provided identifiable benefits arose from such changes. Face-to-face discussions, based on the questionnaire section dealing with current food waste disposal, showed that waste collections from the restaurants were organised completely by private contractors, collecting from storage bins placed in zones away from the catering areas of the restaurant so that the collection activity did not impact on clients. Collection occurred between one and three times per day; and transfer of the waste from preparation areas and plate waste to the collection bins was made at frequent intervals throughout the day. The food waste collection systems were considered to be effective within the constraints of limited space availability and staff experience. Senior managers in the restaurants estimated that their costs of handling the waste, assuming it was treated by anaerobic digestion, would be in the range £19-36/t, but with the addition of other costs such as labour, waste management and procurement and so on, the annual cost of waste disposal for the three restaurants is estimated at about $£ 75000$.

When questions were posed about the vacuum-packing system for food waste management, demonstrated in this research in their restaurants, the senior managers saw the potential operational benefits of the use of the system. They were confident that they could use a wet and dry vacuum system for containing food waste for storage, but they would prefer the system to be operated by private contractors rather than purchasing or hiring their own equipment. The advantages perceived by the restauranteurs were those highlighted for food handling in the research and included: reduction in the volume of waste to be stored; improved hygiene and vermin control in the storage area; ease of stacking of bags containing the vacuum-packed food; and the potential reduction in the number of vehicle trips required for safe removal of the waste from the premises. 


\section{Discussion}

The food waste survey in the three restaurants used as sites for case studies on the development of a new vacuum-packing system for catering food waste confirmed that the major problems associated with waste generation in catering establishments in high-population-density urban areas arise from severe space restrictions on waste storage and a rapid turnover of staff that leads to difficulties in maintaining a work force fully trained in waste management procedures. Although the catering staff in the restaurants studied was generally aware of the potential environmental benefits of effective waste separation and particularly of the food waste, they considered that their high-pressure working conditions were not conducive to applying ideal waste separation and collection regimes. These factors contributed to the fact that a target (WRAP, 2017) of recycling $70 \%$ of catering food and packaging wastes, with the food wastes being recycled through AD or composting, by the end of 2015 was missed even though a Greater London Authority project (LWARB, 2015) showed that a representative sample of hospitality premises would save on average more than $£ 6000$ per annum through a combination of food waste prevention measures and the separation of food waste. In Scotland there is now a regulatory requirement for separation and collection of food waste from all non-household premises that generate more than $5 \mathrm{~kg}$ of food waste per week, in urban areas (Scottish Parliament, 2012), but for the central London restaurants there is no such requirement in English law to reinforce progress towards greater food waste separation for recycling.

The results on the characterisation of food waste in the three restaurants used as case studies in this work showed (Tables 2-4) that plate waste represented the largest single quantity of the waste generated in each case. The food waste from the three restaurants over a complete working week, calculated at approximately $425 \mathrm{~kg}$, would, on the basis of total waste-handling costs and treatment predictions (Lee et al., 2013; Parry et al., 2015), incur a cost of about $£ 1460$ per week.

The key driver of the study is to optimise the capture of food waste from high-density urban environments and to contain this waste in an easy-to-transport receptacle to deliver to treatment plants and maximise recovery of value from the waste. The use of the novel system of vacuum-packing developed in this work for the handling of food waste at source has led to the realisation of the following benefits: $(a)$ in terms of storage and collection: $(i)$ a reduction of $38 \%$ in the volume of food waste to be stored, (ii) a reduction in the physical space required on-site for storage of multiple vacuum packs of waste and (iii) a reduction in the number of vehicle movements required to transfer the wastes to treatment facilities. (b) In terms of treatment: with the containment of the wastes as a sealed unit under sanitised conditions, $(i)$ minimisation of risks to public health; and (ii) preservation of the integrity of the waste as a feedstock, which, stored under sanitised conditions, does not show any significant degradation over a period of $5 \mathrm{~d}$, making the food waste an ideal feedstock for value recovery by AD or IVC. The choice of treatment deployed may be dictated by the nature of the packaging used. For example, IVC and some AD plants may require a biodegradable bag to be used as the packaging medium, while other AD plants have the ability to cope with the separation of plastic bags at the point of reception, where the micron thickness of the plastic may become critical depending on the depackaging equipment used (WRAP, 2009). In the event that the plastic bags cannot be handled in the treatment process, their robustness will allow them to be collected, washed and returned for second use.

For the three restaurants in the case study, the use of the vacuum-packed methodology would result in a total volume reduction of food waste to be collected from 670 to 415 litre/d, a cost saving of $£ 13-16$ per bin lift and considerable reduction in the overall cost.

\section{Conclusion}

A novel system of vacuum-packing for food waste arising from restaurants in high-density urban environments is developed to: (a) contain the food waste, at source, under sanitised conditions; $(b)$ reduce the volume of food waste that has to be stored, particularly in situations where on-site space is at a premium; (c) minimise environmental problems in terms of public health, vermin and odour; $(d)$ reduce the number of vehicle movements required to transfer the wastes to treatment facilities; $(e)$ extend the useful life of the food waste, as an uncontaminated feedstock, for recycling by AD or IVC; and $(f)$ facilitate more effective handling of the food waste at point of reception at the treatment sites, and thereby maximise the recovery value from the collected food waste.

\section{Acknowledgements}

The authors thank Dennis Moore, director of Rothenburg UK for his advice.

\section{REFERENCES}

Alonso-Almeida M, Fernandez R, Soledad Celemin Pedroche $M$ and Santander Astorga P (2017) Revisiting green practices in the hotel industry: a comparison between mature and emerging destinations. Journal of Cleaner Production 140: 1415-1428.

APHA (American Public Health Association) (2016) Standard Method 2540E: for fixed and volatile solids ignited at $550^{\circ} \mathrm{C}$. APHA, Washington, DC, USA. See http://www.standardmethods.org (accessed 15/07/2016).

Baldwin C, Wilberforce N and Kapur A (2001) Restaurant and food service life cycle assessment and development of a sustainability standard. International Journal of Life Cycle Assessment 16(1): 40-49. 
BSI (2011) PAS 100:2011: Specification for composted materials. BSI, London, UK.

Caputo P, Clementi M, Ducoli C, Corsi S and Scudo G (2017) Food chain evaluator, a tool for analyzing the impacts and designing scenarios for the institutional catering in Lombardy (Italy). Journal of Cleaner Production 140: 1014-1026.

Gomez MGC, Grimes SM and Moore D (2008) In-vessel composting of food waste - a catering waste management solution. CIWM Journal 9(1): 19-23.

Hume A, Grimes S and Boyce J (2002) Environmental product attributes in end-of-life management in the UK. Part II: and end-of-life eco-declaration for waste IT and office equipment. International Journal of Environment and Pollution 18(2): 109-125.

Lee P, Parfitt J and Fryer A (2013) The True Cost of Food Waste Within Hospitality and Food Service. Waste and Resources Action Programme (WRAP), Banbury, UK, Technical Report No. HFS001-015.

LWARB (London Waste Recycling Board) (2015) GLA Food Save 2015. LWARB, London, UK. See https://www.london.gov.uk/what-wedo/environment/waste-and-recycling/helping-businesses-reducefood-waste (accessed 06/04/2017).

Okazaki W, Turn S and Flachsbart P (2008) Characterization of food waste generators: a Hawaii case study. Waste Management 28: 2483-2494.

Papargyropoulou E, Wright N, Lozano R et al. (2016) Conceptual framework for the study of food waste generation and prevention in the hospitality sector. Waste Management 49: 326-336.

Parfitt J, Barthel M and MacNaughton S (2010) Food waste within food supply chains: quantification and potential for change to 2050 Philosophical Transactions of the Royal Society B 365: 3065-3081.

Parry A, James K and LeRoux S (2015) Strategies to Achieve Economic and Environmental Gains by Reducing Food Waste. Waste and Resources Action Programme (WRAP), Banbury, UK.
Pirani S and Arafat H (2016) Reduction of food waste generation in the hospitality industry. Journal of Cleaner Production 132: 129-145.

Scottish Parliament (2012) Environmental Protection. The Waste (Scotland) Regulations 2012. Scottish Parliament, Edinburgh, UK, Scottish Statutory Instrument 2012 No. 148.

Tatano F, Caramiello C and Polini T (2017) Generation and collection of restaurant waste: characterization and evaluation at a case study in Italy. Waste Management 61: 423-442.

UN (United Nations) (2016) The Sustainable Development Goals Report 2016. UN, New York, NY, USA, goal 12.3. See https://unstats.un. org/sdgs/report/2016/The $\% 20$ Sustainable $\% 20$ Development $\%$ 20Goals\%20Report\%202016.pdf (accessed 20/02/2018).

WRAP (Waste and Resources Action Programme) (2009) SLR Consulting Limited, Review of Food Waste Depackaging Equipment. Waste and Resources Action Programme (WRAP), Banbury, UK, Technical Report OFW005-001. ISBN: 1-84405-412-8.

WRAP (2013) Oakdene Hollins, Responsibility Partnership and WRAP 2013 Overview of Waste in the UK Hospitality and Food Service Sector. Waste and Resources Action Programme (WRAP), Banbury, UK, Technical Report No HFS001-006.

WRAP (2016a) The Courtauld Commitment 2025. Waste and Resources Action Programme (WRAP), Banbury, UK. See http://www.wrap. org.uk/content/courtauld-commitment-2025-transform-uk-foodand-drink (accessed 06/04/2017).

WRAP (2016b) A Food Waste Recycling Action Plan for England. Waste and Resources Action Programme (WRAP), Banbury, UK. See http://www.wrap.org.uk/sites/files/wrap/A_Food_Waste_ Recycling_Action_Plan_For_England_0.pdf (accessed 06/04/2017). WRAP (2017) Hospitality and Food Service Agreement Final Report. Waste and Resources Action Programme (WRAP), Banbury, UK See http://www.wrap.org.uk/content/hospitality-and-food-serviceagreement-taking-action-waste (accessed 06/04/2017).

\section{How can you contribute?}

To discuss this paper, please email up to 500 words to the editor at journals@ice.org.uk. Your contribution will be forwarded to the author(s) for a reply and, if considered appropriate by the editorial board, it will be published as discussion in a future issue of the journal.

Proceedings journals rely entirely on contributions from the civil engineering profession (and allied disciplines). Information about how to submit your paper online is available at www.icevirtuallibrary.com/page/authors, where you will also find detailed author guidelines. 